\title{
PEMBAGIAN HARTA WARISAN PADA MASYARAKAT \\ ADAT DAYAK PAKPAK OLEH TEMENGGUNG ADAT \\ MENURUT HUKUM ADAT DAYAK PAPAK DI \\ DESA NANGA UNGAI KECAMATAN \\ KAYAN HULU
}

\author{
Tri Minarti \\ Fakultas Hukum Univesitas Kapuas Sintang \\ Jalan YC. Oevang Oeray 92 Sintang \\ email: triminartianwar@gmail.com
}

\begin{abstract}
Dayak Pakpak tribe is one of the Dayak tribes in Sintang regency, it is located at Nanga Ungai village, Kayan Hulu Subdistrict, whereas at there the distribution of inheritance uses a customary law until nowadays.

The research discussion designed toward the performance distribution of inheritance on Dayak Pakpak community by the Temenggung adat which related to the Customary Law of Dayak Papak in Nanga Ungai Village, Kayan Hulu subdistrict.

The approach used in this research is a Sociological Juridical Method. The approach is defined as problem analysis through legal research of factual facts in institution concerned or toward the community which covered as problems handled in the research.

As results, the implementation of inheritance distribution on Dayak Pakpak community by the Temenggung adat are suitable with a customary law of Dayak Papak in Nanga Ungai Village, Kayan Hulu subdistrict, which is implemented
\end{abstract}

by Temenggung with the beneficiary in accordance with the beneficiary's orders for the period of his lifetime, as for the group who gets the inheritance biological child, wife/husband, parents (father/mother:only if the person concerned dies), grandchildren (in case the child is no longer there) and grand children (in case the grandchild is not there).

In conclusion, according to the customary law of Dayak Papak in Nanga Ungai Village, Kayan Hulu District, it is carried out by Temenggung together with the heirs in accordance with the heir's orders during his lifetime. The group who gets the inheritance Natural children, wife / husband, parents (father / mother if the person concerned dies), grandchildren (in this case the child is no longer there) and grandchildren (in this case the grandchild is not there). Then after, if there is a debate in those family mentioned in receiving the assets, it should be resolved by gathering together as means of talk for finding solution and the Head of Custom togetherwith the Temenggung must be engaged. 
Keywords: The distribution of inheritance,

Dayak Pakpak, Temenggung

\section{ABSTRAK}

Suku dayak Pakpak merupakan salah satu suku dayak di Kabupaten Sintang tepatnya Desa Nanga Ungai Kecamatan Kayan Hulu, yang dalam pembagian harta warisan masih menggunkan hukum adat di desa tersebut. Adapun yang menjadi pembahasan bagaimana pelaksanaan pembagian harta warisan pada masyarakat Adat Dayak Pakpak oleh Temenggung Adat Menurut Hukum Adat Dayak Papakdi Desa Nanga Ungai Kecamatan Kayan Hulu. Metode penelitian menggunakan Yuridis Sosiologis yaitu pendekatan masalah melalui penelitian hukum dengan fakta yang ada pada instansi yang bersangkutan ataupun masyarakat sehubungan dengan permasalahan yang ditemui dalam penelitian.

Hasil penelitian bahwa pelaksanaan pembagian harta warisan pada masyarakat adat Dayak Papak oleh Temenggung adat Menurut hukum adat Dayak Papak di Desa Nanga Ungai Kecamatan Kayan Hulu dilaksanakan oleh Temenggung bersama ahli waris sesuai dengan perintah pewaris semasa hidupnya, adapun golongan yang mendapatkan warisan Anak kandung, Istri/ suami, Orang tua (ayah/ ibu kalau yang bersangkutan meninggal), Cucu (dalam hal anak sudah tidak ada) dan Cicit (dalam hal cucu sudah tidak ada)
Kata kunci : Pembagian Harta Warisan, Dayak Pakpak, Temenggung

\section{PENDAHULUAN}

Dayak merupakan sebutan bagi penduduk asli Pulau Kalimantan. Pulau kalimantan terbagi berdasarkan wilayah Administratif yang mengatur wilayahnya masing-masing terdiri dari: Kalimantan Timur ibu kotanya Samarinda, Kalimantan Selatan dengan ibu kotanya Banjarmasin, Kalimantan Tengah ibu kotanya Palangka Raya, dan Kalimantan Barat ibu kotanya Pontianak..

Kelompok Suku Dayak, terbagi lagi dalam sub-sub suku yang kurang lebih jumlahnya 405 sub (menurut J. U. Lontaan, 1975). Masing-masing sub suku Dayak di Pulau Kalimantan mempunyai adat istiadat dan budaya yang mirip, merujuk kepada sosiologi kemasyarakatannya dan perbedaan adat istiadat, budaya, maupun bahasa yang khas. Masa lalu masyarakat yang kini disebut suku Dayak, mendiami daerah pesisir pantai dan sungai-sungai di tiap-tiap pemukiman mereka.

Etnis Dayak Kalimantan menurut seorang antropologi J.U. Lontaan, 1975 dalam Bukunya Hukum Adat dan Adat Istiadat Kalimantan Barat, terdiri dari 6 suku besar dan 405 sub suku kecil, yang menyebar di seluruh Kalimantan. Kuatnya arus urbanisasi yang membawa pengaruh dari luar,seperti melayu menyebabkan mereka menyingkir semakin 
jauh ke pedalaman dan perbukitan diseluruh daerah Kalimantan. ${ }^{1}$

Mereka menyebut dirinya dengan kelompok yang berasal dari suatu daerah berdasarkan nama sungai, nama pahlawan, nama alam dan sebagainya. Misalnya suku Iban asal katanya dari ivan (dalam bahasa kayan, ivan $=$ pengembara $)$ demikian juga menurut sumber yang lainnya bahwa mereka menyebut dirinya dengan nama suku Batang Lupar, karena berasal dari sungai Batang Lupar, daerah perbatasan Kalimantan Barat dengan Serawak, Malaysia. Suku Mualang, diambil dari nama seorang tokoh yang disegani (Manok Sabung/algojo) di Tampun Juah dan nama tersebut diabadikan menjadi sebuah nama anak sungai Ketungau di daerah Kabupaten Sintang (karena suatu peristiwa) dan kemudian dijadikan nama suku Dayak Mualang. Dayak Bukit (Kanayatn/Ahe) berasal dari Bukit/gunung Bawang. Demikian juga asal usul Dayak Kayan, Kantuk, Tamambaloh, Kenyah, Benuag, Ngaju dan lain-lain, yang mempunyai latar belakang sejarah sendiri-sendiri. ${ }^{2}$

Namun ada juga suku Dayak yang tidak mengetahui lagi asal usul nama sukunya. Nama "Dayak" atau "Daya" adalah nama eksonim (nama yang bukan diberikan oleh mayarakat itu sendiri) dan bukan nama endonim (nama yang diberikan oleh masyarakat itu sendiri).

1 https://id-id.facebook.com/notes/ stevanus-agung/sejarah-asal-usul-dayak kaliman$\underline{\tan / 205141046181327 / \text { Hari Selasa } 5 \text { Mei } 2020 \text { Jam }}$ $12.00 \mathrm{wib}$

2 Ibid
Kata Dayak berasal dari kata Daya” yang artinya hulu, untuk menyebutkan masyarakat yang tinggal di pedalaman atau perhuluan Kalimantan umumnya dan Kalimantan Barat khususnya, (walaupun kini banyak masyarakat Dayak yang telah bermukim di kota kabupaten dan propinsi) yang mempunyai kemiripan adat istiadat dan budaya dan masih memegang teguh tradisinya. ${ }^{3}$

Berdasarkan wilayah penyebaran di KalimantanBarat Bangsa Dayak di Kalimantan Barat terbagi berdasarkan sub-sub ethnik yang tersebar diseluruh kabupaten di Kalimantan Barat. Berdasarkan Ethno Linguistik dan cirri cultural gerak tari Dayak di Kalimantan Barat menjadi 4 kelompok besar, 1 kelompok kecil yakni: (1) Kendayan / Kanayatn Grop : Dayak Bukit (ahe), Banyuke, Lara, Darit, Belangin, Bakati” dan lain-lain. Wilayah penyebarannya di Kabupaten Pontianak, Kabupaten Landak, Kabupaten Bengkayang, dan sekitarnya. mempunyai gerak tari, enerjik, stakato, keras. (2) Ribunic / Jangkang Grop/ Bidoih / Bidayuh : Dayak Ribun, Pandu, Pompakng, Lintang, Pangkodatn, Jangkang, Kembayan, Simpakng, dll. Wilayah penyebarannya di Kabupaten Sanggau Kapuas, mempunyai ciri gerak tangan membuka, tidak kasar dan halus.

(3) Iban / Ibanic : Dayak Iban dan sub-sub kecil lainnya, Mualang, Ketungau, Kantuk, Sebaruk, Banyur, Tabun, Bugau, Undup, Saribas, Desa, Seberuang, dan sebagainya. Wilayah penyebarannya di Kabupaten 3 Ibid 
Sambas (perbatasan), Kabupaten Sanggau

/ malenggang dan sekitarnya (perbatasan) Kabupaten Sekadau (Belitang Hilir, Tengah, Hulu) Kabupaten Sintang, Kabupaten Kapuas Hulu, Serawak, Sabah dan Brunai Darusalam. mempunyai ciri gerak pinggul yang dominan, tidak keras dan tidak terlalu halus.(4) Banuaka" Grop : Taman, Tamambaloh dan sub nya, Kalis, dan sebagainya. Wilayah penyebarannya di Kabupaten Kapuas Hulu. ciri gerak mirif kelompok ibanic, tetapi sedikit lebih halus. Kayaanik, punan, bukat dan lainlain. ${ }^{4}$

Selain terbagi menurut ethno linguistik yang terdata menurut jumlah besar groupnya, masih banyak lagi yang belum teridentifikasikan gerak tarinya, karena menyebar dan berpencar dan terbagi menjadi suku yang kecil-kecil. Misalnya Dayak Mali / ayek-ayek, terdapat dialur jalan tayan kearah kab. ketapang. kemudian Dayak Kabupaten Ketapang,Daerah simpakng seperti Dayak Samanakng dan Dayak Kualan, daerah Persaguan, Kendawangan, daerah Kayong, Sandai, daerah Krio, Aur kuning. Daerah Manjau dsb.

Kemudian Dayak daerah Kabupaten Sambas, yaitu Dameo / Damea, Sungkung daerah Sambas dan Kabupaten Bengkayang dan sebagainya. Kemudian daerah Kabupaten Sekadau kearah Nanga Mahap dan Nanga Taman, Jawan, Jawai, Benawas, Kematu 4 http://hamiddarmadi.blogspot.com/2017/02/ ayak-asal-usul-dan-penyebarannya-di.htm diakses Hari Selasa 5 Maret 2020 Jam 12.00 wib dan lain-lain. Kemudian Kabupaten Melawi, yaitu: dayak Keninjal(mayoritas tanah pinoh;antara lain desa ribang rabing, ribang semalan, madya raya, rompam, ulakmuid, maris dan lain-lain) dayak Kebahan (antara lain desa:poring,nusa kenyikap, Kayu Bunga, dan lain-lain yang memiliki tari alu dan tari belonok kelenang yang hampir punah), dayak Linoh (antara lain desa:Nanga taum,sebagian ulak muid, mahikam dan lain-lain), dayak pangen (Jongkong, sebagian desa balaiagas dan lain-lain), dayak kubing (antara lain desa sungai bakah/sungai mangat, nyanggai, nanga raya dan lain-lain), dayak limai (antara lain desa Tanjung Beringin, tain, menukung, ela dan lain-lain), dayak undau, dayak punan, dayak ranokh/anokh (antara lain sebagian di desa batu buil, sungai raya dan lain-lain), dayak sebruang (antara lain didesa tanjung rimba, piawas dan lain-lain), dayak Ot Danum ( masuk kelompok kal-teng), Leboyan. ${ }^{5}$

Demikian juga halnya dengan adat dan tradisi disetiap wilayah yang berbeda namun hal itu menandakan bahwa masyarakat, suku dan wilayah mempunyai ciri khas dari masing-masing daerah terutama masyarakat yang menggambarkan tradisi dan budaya. Nilai adat tersebut dituangkan dalam kehidupan masyarakat sehingga masyarakat menganggap bahwa aturan adat dan kebiasaan menjadi wadah untuk menyelesaikan suatu permasalahan baik dalam perkara pidana

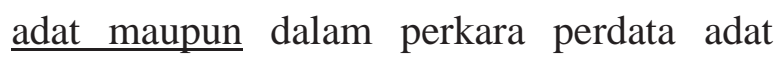
5 Ibid 
yang salah satunya adalah waris adat, waris adat merupakan salah satu kewajiban yang disampaikan kepada penerima waris apabila pewaris menginginkan agar harta kekayaan yang dimiliki dibagi kepada penerus ataupun keturunannya, sehingga pembagian harta waris yang dilakukan agar dapat menjadi perdamaian bagi mereka yang menerimanya.

Dalam penelitian ini Penelitiakan mengkaji bagaimanakah pembagian harta waris pada masyarakat Dayak Papak oleh Temenggung adat di Desa Nanga Ungai Kecamatan Kayan Hulu Kabupeten Sintang, penyelesaian pembagian waris adat pada masyarakat dayak Papak bertujuan agar para penerima waris adat tidak berselisih yang dapat saja menimbulkan ketidak harmonisan dalam keluarga, oleh sebab itu pembagian waris adat yang dilakukan oleh Temenggung adat dengan cara keterbukaan di depan penerima waris dan saksi serta dihadapan keluarga besar dari yang mewariskan, dengan adanya pembagian waris oleh Temenggung adat terhadap penerima waris maka bagi para pihak yang menerima waris dapat menerima sesuai dengan aturan-aturan adat yang berlaku pada masyarakat Dayak Papak. Berdasarkan hasil observasi Penelitipada saat pra penelitian di Desa Nanga Ungai Kecamatan Kayan Hulu bahwa dalam pembagian waris adat yang dilakukan oleh Temenggung adat masih ada pihak-pihak penerima waris adat yang merasa tidak puas dari keputusan yang diambil oleh
Temenggung adat pada hal keputusan dari Temenggung adat berdasarkan buku adat yang berlaku, pembagian waris adat menurut buku adat dan kebiasaan masyarakat dayak papak merupakan salah satu kewajiban yang harus disampaikan apabila pewaris tersebut sudah meninggal dunia ataupun pewaris sudah memberikan kepada ahli waris untuk memanfaatkan serta mengelola kebun dan lahan untuk kepentingan pewaris dalam arti pewaris masih dalam keadaan hidup. Ketidak puasan dari para pihak yang menerima waris adat terjadi karena pembagian harta waris dianggap tidak sesuai dengan harta waris yang ditinggalkan oleh pewaris.

Harta waris adalah hal - hal yang dapat diwarisi dari si pewaris, pada prinsipnya yang dapat diwarisi hanyalah hak - hak dan kewajiban dalam lapangan harta kekayaan. Hak dan kewajiban tersebut berupa, Aktiva ( sejumlah benda yang nyata ada dan atau berupa tagihan atau piutang kepada pihak ketiga, selain itu juga dapat berupa hak imateriil, seperti, hak cipta ); Passiva ( sejumlah hutang pewaris yang harus dilunasi pada pihakketiga maupun kewajiban lainnya ). Dengan demikian, hak dan kewajiban yang timbul dari hukum keluarga tidak dapat diwariskan.

Menurut Buku adat Suku Dayak Kecamatan Kayan Hulu memberikan penjelasan tentang pengertian dari warisadat adalah "Sebagai akibat dari sebuah perkawinan selain melahirkan keturunan 
tentu pula menimbulkan petalian keluarga dan melahirkan hubungan kekerabatan. Dalam perkawinan juga / rumah tanggaselain memperoleh keturunan harta benda, menimbulkan hak dan kewajiban baik terhadap anak, cucu, cicit bahkan samapi dengan buyut, demikian pula sebaliknya menimbulkan kewajiban dan hak terhadap orang tua bapak/ mamak, kakek, nenek dan datuk, dan lain sebagainya sehingga menimbulkan waris. ${ }^{6}$

Berdasarkan penjelasan diatas bahwa waris dilakukan sebagai akibat dari hubungan perkawinan sehingga menimbulkan hak dan kewajiban bagi pewris maupun penerima waris. Menurut Buku adat Suku Dayak Kecamatan Kayan Hulu adat hak mewaris ada beberapa tingkatan antara lain :

(1) Anak kandung

(2) Istri/ suami

(3) Orang tua (ayah/ibu kalau yang bersangkutan meninggal)

(4) $\mathrm{Cucu}$ (dalam hal anak sudah tidak ada)

(5) Cicit (dalam hal cucu sudah tidak ada) ${ }^{7}$

Demikian pula kebalikannya keatas, mulai orang tuanya baru kakek, nenek, datuk, dan dalam hal waris terdekat sudah tidak ada, maka harta benda tersebut kembali pada pengurus adat atau kampung untuk dijadikan hak bersama (kerama). ${ }^{8}$

Dari penjelasan diatas bahwa penerima

6 Buku adat Dayak Kecamatan Kayan Hulu Kabupaten Sintang hlm: 6

7 Buku adat Dayak Kecamatan Kayan Hulu Kabupaten Sintang hlm: 6

8 Buku adat Dayak Kecamatan Kayan Hulu Kabupaten Sintang hlm: 6 waris menurut golongan-golongan yang ditentukan berdasarkan adat dan kebiasaan masyarakat setempat. Ahli waris menurut undang - undang ( abintestato ) Ahli waris ini didasarkan atas hubungan darah dengan si pewaris atau para keluarga sedarah. Ahli waris ini terdiri atas 4 golongan. Antara lain :

(1) Golongan I, terdiri dari anak - anak, suami ( duda ) dan istri ( janda ) si pewaris;

(2) Golongan II, terdiri dari bapak, ibu ( orang tua ), saudara - saudara si pewris;

(3) Golongan III, terdiri dari keluarga sedarah bapak atau ibu lurus ke atas ( seperti, kakek, nenek baik garis atau pancer bapak atau ibu ) si pewaris;

(4) Golongan IV, terdiri dari sanak keluarga dari pancer samping ( seperti, paman, bibi).

Sedangkan Hukum waris ( erfrecht ) yaitu seperangkat norma atau aturan yang mengatur mengenai berpindahnya atau beralihnya hak dan kewajiban ( harta kekayaan ) dari orang yang meninggal dunia ( pewaris ) kepada orang yang masih hidup ( ahli waris) yang berhak menerimanya. Atau dengan kata lain, hukum waris yaitu peraturan yang mengatur perpindahan harta kekayaan orang yang meninggal dunia kepada satu atau beberapa orang lain.

\section{Pengertian Adat}

Hukum adat merupakan hukum asli yang berlaku bagi masyarakat adat Indonesia. Adat sendiri berasal dari bahasa Arab yang 
berarti kebiasaan. Kebiasaan tersebut ditiru dan akhirnya berlaku untuk seluruh anggota masyarakat. Hukum adat tidak tertulis akan tetapi dipatuhi oleh anggota masyarakat adat. Hukum adat merupakan bentuk dari adat yang memiliki akibat hukum. Hukum adat berbeda dengan hukum tertulis ditinjau dari bentuk sanksi yang diberikan kepada orang yang melakukan pelanggaran. Bentuk sanksi hukum adat menitikberatkan pada bagian moral serta material, hukum adat tidak mengenal penjara sebagai tempat para terpidana menjalani hukuman yang telah ditetapkan oleh hakim. ${ }^{9}$ Ada 3 (tiga) persyaratan agar adat / kebiasaan dapat menjadi hukum adat / hukum kebiasaan yaitu:

(1) Syarat Material adanya kebiasaan atau tingkah laku yang tetap di ulang-ulang, artinya suatu rangkaian perbuatan yang sama, yang berlangsung untuk beberapa waktu lamanya.

(2) Syarat intelektual (opino necessitates) artinya kebiasaan/ adat itu harus menimbulkan keyakinan pendapat umum demikianlah seharusnya (opino necessitates), bahwa perbuatan itu merupakan kewajiban hukum. Kebiasaan itu harus dilakukan karena keyakinan, bahwa hal itu patut secara obyektif dilakukan, bahwa dengan melakukan itu berkeyakinan telah melakukan kewajiban hukum.

9 Bushar Muhammad, 2006, Asas-Asas Hukum Adat, Jakarta: PT. Pradnya Paramita. Hlm. 19.
(3) Adanya akibat hukum atau menimbulkan akibat hukum apabila adat atau kebiasaan itu dilanggar. ${ }^{10}$

Sedangkan Kata adat berasal dari bahasa Arab yang kemudian diadopsi ke dalam bahasa Indonesia yang baku. Kata adat berasal dari kata "ad" yang mempunyai derivasi kata “al中adat yang berarti sesuatu yang diulangulang atau dapat dikatakan sebagai kebiasaan. Adat diartikan sebagai "aturan (perbuatan dsb) yang lazim diturut atau dilakukan sejak dahulu kala". ${ }^{11}$

Sedangkan pengertian Kebiasaan merupakan perbuatan yang diulang-ulang dalam bentuk yang sama. Perbuatan itu diulang-ulang membuktikan bahwa orang menyukainya. Jadi kebiasaan (Folkways) merupakan tata cara bertindak yang digemari oleh masyarakat sehingga dilakukan berulangulang oleh banyak orang. Kebiasaan memiliki kekuatan yang lebih besar dari pada tata cara, misalnya memberikan salam waktu bertemu, berterimakasih, menyuci tangan sebelum dan sesudah makan, membungkukkan badan sebagai tanda penghormatan kepada orang yang lebih tua. ${ }^{12}$

Demikian halnya proses hukumadat, sebelum keberadaannya diakui oleh masyarakat baik secara yuridis normative

10 Soerojo Wigjodiporo, Pengantar dan AsasAsas Hukum Adat, Haji Masagung, Jakarta, Hlm : 20

11 Wikipediabahasa Indonesia, ensiklopedia bebas, https://id.wikipedia.org/wiki/Adat, diakses pada Hari Selasa 5 Mei 2020 Jam 12.00 wib

12 ht tps: // mellapuspi ta.wordpress. com/2017/04/14/perbedaan-peradaban-budaya-tradisi-adat-istiadat-dan kebiasaan/ diakses Hari Selasa 5 
filosofis maupun sosiologis, tentunya tidak terlepas dari sebuah siklis yang menjadi dasar atau sumber pembentukannya sehingga lahirlah sesuatu yang dikenal dengan hukum adat. $^{13}$

Menurut I Gede AB, Wiranata dalam memberikan batasan adat dalam ragam pengertian sebagai berikut :

(1) Adat sebagai aturan (pembuatan dan sebagainya) yang lazim diturut atau dilakukan sejak dahulu kala.

(2) Adat sebagai kebiasaan, cara (kelakuan dan sebagainya), yang sudah menjadi kebiasaan.

(3) Adat sebagai cukai menurut peraturan yang berlaku (dipelabuhan).

(4) Adat sebagai wujud gagasan kebudayaan terdiri atas nilai-nilai budaya, norma, hukum, dan atuiran-aturan yang satu dengan yang lainnya berkaitan menjadi satu system. ${ }^{14}$

Dengan melihat pendapat diatasbahwa batasan adat merupakan wujud darinilainilaibudaya,normadanaturan aturan yang berlaku pada masyarakat dipatuhi serta ditaati. Sehubungan dengan hal tersebut menurut Hazairin (dalam bukunya Bushar Muhammad mengatakan bahwa: "Adat itu adalah

Mei 2020 Jam 12.00 wib

13 Mstari Pide Suryaman, 2014 Hukum Adat Dahulu, Kini dan Akan Datang Prenademia Grup Jahakarta Hlm.1

14 I Gede A.B. Wiranata, 2005 Hukum Adat Indonesia, Perkembangannya dari Masa Kemasa, PT.Citra Aditiya Bakti, Bandung, Hlm.3 renapam (endapan) kesusilaan dalam masyarakat, yaitu bahwa kaidah- kaidah adat itu berupa kaidah-kaidah kesusilaan yang kebenarannya yang telah mendapat pengakuan umum dalam masyarakat itu". ${ }^{15}$

Sedangkan menurut Kusumadi Pudjojosewojo, mengatakan : "Bahwaadat adalah tingkah laku oleh dan dalam suatu masyarakat (sudah, sedang, akan) diadatkan, adat ituada yang tebal dan ada yang tipis senantiasa menebal dan menipis". ${ }^{16}$

Menurut Van Vollenhoven hukum adat adalah :"Aturan prilaku yang berlaku bagi orang-orang pribumi danorang-orang timur asing, yang disuatupihak mempunyai sanksi (sehingga disebut hukum) dan dilain pihak tidak dikodifikasi (sehuingga dikatakan adat)". ${ }^{17}$

Aturan- aturan adat yang mempunyai sanksi dan tegas serta bersumber dari rasa keadilan dalam masyarakat setempat hukum adat itu berlaku, yang keberadaannyadipertahankan secara turun temurun baik secara lisan maupun tulisan, sebagaimana yang diutarakan oleh Soerojo wignjodipoero hukum adat

15 Bushar Muhhamad, 1981, Asas-Asas Hukum Adat Suatu Pengantar, Pradya Paramita, Jakarta Hlm. 20

16 Kusumadi, 2004, Pedoman Pelajaran Tata Hukum, Aksara Baru Jakarta. Hlm. 45

17 I Gede A.B. Wiranata,op.cit Hlm.11 
adalah sebagai berikut : "Suatu komplek norma-norma yang sumber pada perasaan keadilan rakyat yangselalu berkembang serta meliputi peraturan-peraturan tingkah laku manusia dalam kehidupan sehari- hari dalam masyarakat, sebagian besar tidak tertulis, senantiasa ditaati dan dihormati oleh rakyat, karena mempunyai akibat hukum atau sanksi". ${ }^{18}$ Sedangkan pengertian hukum adat menurut Soekamto dalam bukunya Menuju Hukum Adat Indonesia : "Komplek adatadat inilah yang kebanyakan tidak dikitabkan, tidak dikodifikasikan dan bersifat paksaan mempunyai sanksi (dari itu hukum), jadi mempunyai akibat hukum, komplek ini disebut hukum adat". ${ }^{19}$ "Adat itu adalah renapam (endapan) kesusilaan dalam masyarakat, yaitu bahwa kaidah- kaidah adat itu berupa kaidah-kaidah kesusilaan yang kebenarannya yang telah mendapat pengakuan umum dalam masyarakat itu". ${ }^{20}$

Menurut R. Soepomo dalam pidatonya pada konfrensinya Asia tenggara di Washington 14 Agustus1952 menjelaskan pengertian hukum adat menyebutkan:

Hukum adat adalah

18 Soerojo Wigjodipoero,op.cit Hlm.14

19 Soekanto, Meninjau Hukum Adat Indonesia Suatu Pengatar Untuk Mempelajari Hukum Adat, CV Rajawali Jakarta, Hlm. 2

20 Bushar Muhhamad,ibid. hukum nonstatutair yang sebagian besar adalah hukum kebiasaan dan sebagian kecil adalah hukum Islam. Ia berurat berakar pada kebudayaan tradisional. Sebagian hukum yang hidup, dia menjelmakan persatuan hukum yang nyata dari masyarakat / rakyat. Ia senantiasa tumbuh dan berkembang seperti hidup itu sendiri. ${ }^{21}$ Timbulnya reaksi dari masyarakat adat, atas pelanggaran hukum atau perbuatan yang menyebabkan terjadinya peristiwa adat sehingga mengakibatkan ketidak seimbanganantar kelompok masyarakat dan memperngaruhi kehidupan manusia dan alam sekitarnya merupakanperbuatan yang menyelenggarakan adat sebagai hukum yang selama ini dijunjung tinggi oleh masyarakatadat setempat.

Dimana di dalam buku bab-bab tentang Hukum Adatkarya Supomo yang dikutip kembali oleh Bushar Muhammad mengatakan“ Bahwa delik adat adalah suatuperbuatan sepihak dari seseorang atau kumpulan perorangan, mengancam atau menyinggung atau mengganggu keseimbangan dalam kehidupan persekutuan. Bersifat material dan immaterial terhadap orang peroranganatau terhadap masyarakat berupa persekutuan. Tindakan atau perbuatan

21 I Gede A.B. Wiranata, op.cit Hlm.17 
yang demikian mengakibatkan suatu keseimbangan yang telah tergangguantara lain dengan berbagai jalan dan cara, dengan pembayaran adat berupa barang, uang mengadakan selamatan memotong hewan besaratau kecil dan lain sebagainya". ${ }^{22}$ Dengan melihat pengertian adat diatas dapat Penelitisampaikan bahwa adat merupakan suatu aturan yang peraturan-peraturan mengatur tingkah laku manusia dalam kehidupan sehari- hari dalam masyarakat, sebagianbesar tidak tertulis, senantiasa ditaati dan dihormati oleh rakyat, karena mempunyai akibat hukum atau sanksi.

\section{METODE PENELITIAN}

Metode pendekatan yang digunakan dalam penelitian ini adalah Metode Yuridis Sosiologis yaitu pendekatan masalah melalui penelitian hukum dengan fakta yang ada pada instansi yang bersangkutan ataupun masyarakat sehubungan dengan permasalahan yang ditemui dalam penelitian ${ }^{23}$

Dengan metode pendekatan terhadap kelompok masyarakat di Desa Nanga Ungai Kecamatan Kayan Hulu Kabupaten Sintang artinya Penelitimencari secara langsung dan mendapatkan data dari kelompok masyarakat dan menyesuaikan dengan peraturan hukum

22 Bushar Muhammad, 2000, Pokok-Pokok Hukum Adat, Pradya Paramita, Jakarta, Hlm.61

23 Soerjono Soekanto, 2006.Pengantar Penelitian Hukum, universitas Indonesia, Jakarta, Hlm.12 adat yang dipergunakan.

\section{PEMBAHASAN}

\section{A. Pelaksanaan Pembagian Harta Warisan \\ Pada Masyarakat Adat Dayak Papak oleh Temenggung adat Menurut hukum adat Dayak Papak di Desa Nanga Ungai Kecamatan Kayan Hulu}

Harta waris merupakan salah satu harta yang ditinggalkan oleh seseorang apabila pewaris tersebut sudah dinyatakan meninggal, harta waris diberikan berdasarkan persetujuan dari pewaris kepada penerima waris. Menurut Buku adat Suku Dayak Kecamatan Kayan Hulu memberikan penjelasan tentang pengertian dari waris adat adalah "Sebagai akibat dari sebuah perkawinan selain melahirkan keturunan tentu pula menimbulkan petalian keluarga dan melahirkan hubungan kekerabatan. Dalam perkawinan juga / rumah tangga selain memperoleh keturunan harta benda, menimbulkan hak dan kewajiban baik terhadap anak, cucu, cicit bahkan samapi dengan buyut, demikian pula sebaliknya menimbulkan kewajiban dan hak terhadap orang tua bapak/mamak, kakek, nenek dan datuk, dan lain sebagainya sehingga menimbulkan waris. ${ }^{24}$ Berdasarkan hasil wawancara peneliti, Temenggung adat bapak Bujang Rantai mengatakan bahwa, " Harta waris dapat diberikan kepada keturunan yang

24 Buku adat Dayak Kecamatan Kayan Hulu Ka- 
meninggal baik sedarah dibawahnya maupun sedarah diatasnya, yang artinya bisa diberikan kepada anak-anaknya, atau cucu, maupun kepada kedua orang tuanya apabila anak, cucu belum ada, bahkan bisa kesamping apabila orang tua atau anak, cucu dari pemberi warisan tidak ada yang artinya diberikan kepada paman, bibi dari pihak bapak atau ibu. ${ }^{25}$

" Harta waris diberikan sebagai akibat dari perkawinan yang dilakukan oleh pewaris, oleh sebab itu maka penerima waris merupakan orang berdasarkan keturunannya. berikut ini penerima waris. Menurut Bukuadat Suku Dayak Kecamatan Kayan Hulu adat hak mewaris dengan beberapa tingkatan antara lain :

\section{(1) Anak kandung}

(2) Istri/ suami

(3) Orang tua (ayah/ibu kalau yang bersangkutan meninggal)

(4) Cucu (dalam hal anak sudah tidak ada)

(5) Cicit (dalam hal cucu sudah tidak ada $)^{26}$ Demikian pula kebalikannya keatas, mulai orang tuanya baru kakek, nenek, datuk, dan dalam hal waris terdekat sudah tidakada, maka harta benda tersebut kembali pada pengurus adat atau kampung untuk dijadikan hak bersama (kerama). ${ }^{27}$ Dengan melihat penjelasan diatas bahwa penerima waris

bupaten Sintang Hlm: 6

25 Hasil wawancara Penelitidengan temenggng adat Desa Nanga Ungai Kecamatan Kayan Hulu Kabupaten Sintang.

26 Buku adat Dayak Kecamatan Kayan Hulu Kabupaten Sintang Hlm: 6

27 Buku adat Dayak Kecamatan Kayan Hulu Kabupaten Sintang Hlm: 6 menurut golongan-golongan yang ditentukan berdasarkan adat dan kebiasaan masyarakat setempat. Ahli waris menurut undang - undang (abintestato ) Ahli waris ini didasarkan atas hubungan darah dengan si pewaris atau para keluarga sedarah.

Berdasarkan hasil wawancara Peneliti dengan Temenggung adat Bapak Bujang Rantai mengatakan bahwa "harta waris yang diberikan sepenggalan dari orang yang meninggal merupakan kewajiban untuk diberikan, apabila keluarga yang ditinggalkan terjadi perdebatan dalam menerima harta tersebut maka akan diselesaikan dengan cara kumpul bersama dan melibatkan ketua adat bersama temenggung untuk membahas dari harta yang diberikan oleh pewaris atau orang yang telah meninggal". ${ }^{28}$

Dalam pembagian waris adat yang dilakukan di Desa nga Ungai Kecamatan Kayan Hulu Kabupaten Sintang dapat saja dilakukan dengan cara apabila pewaris sebelum meninggal sudah memberikan penjelasan terlebih dahulu kepada anak, orang tua maupun keluarga untuk menjatuhkan harta waris kepada orang yang diucapkan, secara atomatis harta yang ditinggalkan akan diberikan kepada disebutkan namanya sebelum pewaris meninggal dunia. ${ }^{29}$

Dengan melihat uraian-uraian diatas

28 Hasil wawancara Peneliti dengan temenggng adat Desa Nanga Ungai Kecamatan Kayan Hulu Kabupaten Sintang.

29 Hasil wawancara Penelitidengan temenggng adat Desa Nanga Ungai Kecamatan Kayan Hulu Kabupaten Sintang. 
bahwa Hukum waris (erfrecht) yaitu seperangkat norma atau aturan yang mengatur mengenai berpindahnya atau beralihnya hak dan kewajiban (harta kekayaan) dari orang yang meninggal dunia (pewaris) kepada orang yang masih hidup (ahli waris) yang berhak menerimanya. Atau dengan kata lain, hukum waris yaitu peraturan yang mengatur perpindahan harta kekayaan orang yang meninggal dunia kepada satu atau beberapa orang lain.

Berdasarkan hasil wawancara Penelitidengan salah satu yang menerima warisan Bapak Entom menjelaskan bahwa, harta waris diberikan kepada masing-masing keluarga menurut tingkatan saudara, harta waris yang ditinggalkan oleh bapak (pewaris) berupa tanah dan kebun, rumah, harta tersebut di berikan sebelum orang tua meninggal dan dipesankan kepada ibu (masih hidup) bahwa harta tersebut dibagi dengan rata dan seadiladilnya, untuk kepentingan dan kesejahteraan anak. dengan dibaginya harta peninggalan orang tua tersebut maka masing-masing dari sudara menggarap dan memanfaatkan lahan sesuai dengan ucapan dan omongan yang disampaikan oleh bapak (pewaris). ${ }^{30}$

Dari penjelasan diatas bahwa harta waris yang ditinggalkan oleh pewaris dapat dipergunakan dan dimanfaatkan oleh penerima waris untuk kepentingan penerima waris. Berdasarkan hasil wawancara Penelitidengan

30 Hasil wawancara Penelitidengan penerima warisan di Desa Nanga Ungai Kecamatan Kayan Hulu Kabupaten Sintang. bapak Bojan selaku kepala suku desa Nanga Ungai menyampaikan bahwa harta waris yang telah disampaikan oleh orang yang meninggal waktu semasa hidupnya walaupun tanpaada tulisan yang menyertainya maka hartatersebut berhak diberikan kepada orang yang menerima sesuai dengan omongan maupun ucapan dari pewaris. karena hal tesebutsudah menjadi kebiasaan bagi masyarakat di desa Nanga ungai Kecamatan kayan hilir Kabupaten Sintang. ${ }^{31}$

\section{KESIMPULAN}

Berdasarkan hasil penelitian maka dapat di simpulkan bahwa pelaksanaan pembagian harta warisan pada masyarakat adat Dayak Papak oleh Temenggung adat Menurut hukum adat Dayak Papak di Desa Nanga Ungai Kecamatan Kayan Hulu dilaksanakan oleh Temenggung bersama ahli waris sesuai dengan perintah pewaris semasa hidupnya, adapun golongan yang mendapatkan warisan Anak kandung, Istri/ suami, Orang tua (ayah/ ibu kalau yang bersangkutan meninggal), Cucu (dalam hal anak sudah tidak ada) dan Cicit (dalam hal cucu sudah tidak ada) dan apabila keluarga yang ditinggalkan terjadi perdebatan dalam menerima harta tersebut maka akan diselesaikan dengan cara kumpul bersama tetap melibatkan ketua adat bersama Temenggung.

31 Hasil wawancara Penelitidengan Kepala Suku di Desa Nanga Ungai Kecamatan Kayan Hulu Kabupaten Sintang. 


\section{SARAN}

Berdasarkan hasil kesimpulan peneliti sarankan pelaksanaan pembagian harta warisan pada masyarakat adat Dayak Papak oleh Temenggung adat Menurut hukum adat Dayak Papak di Desa Nanga Ungai Kecamatan Kayan Hulu sebelum pewaris meninggal, pewaris harus menghadirkan Temenggung dalam membagikan harta warisan agar memudahkan dalam membagi harta warisan kepada yang mewarisi.

\section{DAFTAR PUSTAKA}

\section{Buku}

Bushar Muhammad, Asas-Asas Hukum Adat, Jakarta : PT. Pradnya, 2006.

I Gede A.B. Wiranata, Hukum Adat Indonesia, Perkembangannya dari Masa Kemasa, Bandung : PT.Citra Aditiya Bakti, 2005.

Kusumadi, Pedoman Pelajaran Tata Hukum, Jakarta : Aksara Baru, 2004.

Mstari Pide Suryaman, Hukum Adat Dahulu, Kini dan Akan Datang, Jahakarta :Prenademia Grup, 2014.

Soerjono Soekanto, Pengantar Penelitian

Hukum, universitas Indonesia, Jakarta, 2006.

Soerojo Wigjodiporo, Pengantar dan AsasAsas Hukum Adat, Jakarta : Haji Masagung.

Buku adat Dayak Kecamatan Kayan Hulu Kabupaten Sintang

\section{Sumber Internet}

https://id-id.facebook.com/notes/stevanusagung/sejarah-asal-usul-dayak kaliman$\underline{\tan / 205141046181327 /}$ Hari Selasa 5 Mei 2020 Jam 12.00 wib http://hamiddarmadi.blogspot.com/2017/02/ ayak-asal-usul-dan-penyebarannya-di. htm diakses Hari Selasa 5 Maret 2020 Jam 12.00 wib

Wikipediabahasa Indonesia, ensiklopedia bebas, https://id.wikipedia.org/wiki/Adat, diakses pada Hari Selasa 5 Mei 2020 Jam $12.00 \mathrm{wib}$

ht tps://mellapuspita.wordpress. com/2017/04/14/perbedaan-perad$\underline{\text { aban-budaya-tradisi-adat-istiadat-dan }}$ kebiasaan/ diakses Hari Selasa 5 Mei 2020 Jam 12.00 wib 